Article

\title{
Optimization of Operating Parameters on Dry Grinding of Calcite in a Stirred Media Mill Using the Box-Behnken Design
}

\author{
Diler Katircioglu-Bayel \\ Department of Mining Engineering, University of Nigde Omer Halisdemir, Central Campus, \\ 51240 Nigde, Turkey; dkatircioglu@ohu.edu.tr
}

Received: 20 January 2020; Accepted: 24 February 2020; Published: 9 March 2020

\begin{abstract}
The optimization of the operating parameters of a stirred media mill in the dry grinding of calcite was investigated. A three-level Box-Behnken design was used for the purpose of examining the impact of four independent factors, the stirrer speed (SS), grinding time (GT), media filling ratio (MFR), and solid mass fraction (SMF), on the product particle size $\left(\mathrm{d}_{50}\right)$. For the purpose of establishing an empirical correlation between operating parameters and responses, a series of experiments were carried out. Variance analysis showed a reasonably good value for $d_{50}\left(R^{2}=0.965\right)$. According to the software solutions, the optimum conditions for minimizing the $\mathrm{d}_{50}$ size were found to be $573 \mathrm{rpm}$ stirrer speed, 11.18 min grinding time, $63 \%$ media filling ratio, and $11.52 \%$ solid mass fraction, with $3.78 \mu \mathrm{m}$ for the $\mathrm{d}_{50}$ size. To verify the improvement of grinding, verification tests were performed using the above-mentioned optimum conditions and the average $d_{50}$ size and standard deviation were found to be $3.83 \mu \mathrm{m}$ and 0.025 , respectively. The average $\mathrm{d}_{50}$ value obtained was smaller than those obtained in the 27 tests. Furthermore, when the optimum result obtained from the experiments was compared with the result obtained using the software, a $22 \%$ energy saving was achieved. The impacts of grinding on the structural characteristics of calcite particles were characterized by XRD analysis. XRD measurements indicated that no change was observed in the peak areas of ground calcite specimens compared to the untreated calcite specimen.
\end{abstract}

Keywords: dry grinding; operating parameters; calcite; experimental design; optimization

\section{Introduction}

Grinding is one of the oldest production techniques used by humans. Although the process originates from centuries of experience, it remains important and represents an extremely important area of research. Calcium carbonate $\left(\mathrm{CaCO}_{3}\right)$ is a raw material which is found widely in nature. It is a mineral which is considered to be a filler because of its low price and stable properties. It is generally white in color, has a hexagonal crystal system and a Mohs hardness of 3.0. Natural calcium carbonate, or precipitated calcium carbonate, is used as a filler material at different ratios. $\mathrm{CaCO}_{3}$ represents the filler that is utilized most frequently in the plastic, paper, rubber, paint and ink industries because it is available around the world, is present in a ready-to-use form, and has low cost, excellent whiteness, incombustibility and inertness, and low oil-absorbency and water adsorption [1-3]. Deodhar et al. [4] used nano-sized calcium carbonate mineral as a flame retardant in addition to polypropylene and found a significant decrease in heat emission rates. $\mathrm{CaCO}_{3}$ is also used as sealant formulations in the silicone industry [5].

Many parameters may influence the outcomes of dry grinding in stirred media mills. It is possible to classify such parameters as the mill's design properties (e.g., impeller types, the features of impeller arms, the length/diameter ratio of the mill, the orientation of the shaft), vertical [6-8] or horizontal [9-12] 
and operating parameters (e.g., grinding time [7,13-15], stirrer speed [6,9,13,15-18], media loading, type and size $[13,19,20]$, grinding type. The information obtained from these studies shows that dry stirred media mills are still in an early to intermediate stage of development. A classic factor in a time approach can lead to the failure to identify and connect basic and interaction impacts and optimize grinding parameters [21]. To date, a lot of studies have been carried out to produce fine and ultrafine materials in a stirred media mill. However, few studies have been conducted to assess operating parameters with response surface methodology (RSM) [14,22].

RSM represents a set of mathematical and statistical techniques used in the design of experiments, the establishment of models, the control of the impacts of parameters, and the investigation of the optimum conditions of each factor for the desired responses [23]. Thus, it is widely used in many contemporary mineral processing areas [24-30]. The Box-Behnken design (BBD) in RSM is a significant design tool that is utilized to reduce the number of experiments, as well as time and cost. The BBD provides accurate information from a lower number of experiments and the interactive impacts of operating parameters on all responses [31]. In this context, Celep et al. [22] utilized a four-factor three-level factorial design for their analysis of the impact of a number of parameters of a stirred mill on the ultra-fine grinding of refractory $\mathrm{Au} / \mathrm{Ag}$ ores. The grinding results were evaluated by $\mathrm{d}_{80}$. Following this study, Celep and Yazıc1 [14] investigated the effects of certain operating parameters on ultra-fine grinding of cyanidation plant tailings at three different factors and three levels by utilizing the Box-Behnken design.

In this research, a three-level Box-Behnken design was used for the purpose of examining the impact of four independent factors-stirrer speed, grinding time, media filling ratio, and solid mass fraction-on the product particle size $\left(\mathrm{d}_{50}\right)$ in the dry grinding of calcite in a stirred media mill. To optimize these multiple factors, it was possible to implement the conventional method of "changing one factor at a time." However, the above-mentioned possibility was excluded, since it is time-consuming and does not guarantee achieving the optimum set of parameters. As an alternative, the Box-Behnken design, which is considered a much more reliable approach, was chosen because it is based on a mathematical model [22].

This study has brought a new perspective to our understanding of the efficient and effective use of material, energy, and time in grinding.

\section{Materials and Methods}

\subsection{Materials}

The calcite specimen acquired from Mertas (Nigde, Turkey) was utilized in this research. The samples were oven-dried at $60^{\circ} \mathrm{C}$ to a constant weight. The chemical properties of the calcite specimen measured by X-ray fluorescence (XRF) are presented in Table 1. A pycnometer was utilized to detect the specific gravity of the calcite powder. The particle size distribution of the feed material that was characterized from dry sieving is presented in Figure 1.

Yttria-stabilized zirconia $\left(\mathrm{ZrO}_{2}\right)$ grinding media $\left(3 \mathrm{~mm}\right.$ ) (chemical composition: $93 \% \mathrm{ZrO}_{2}, 5 \%$ $\mathrm{Y}_{2} \mathrm{O}_{3}$, and $2 \%$ others) with high density $\left(6000 \mathrm{~kg} / \mathrm{m}^{3}\right)$, obtained from Cenotec Co., Ltd., Haman, Korea, were used in conducting grinding tests.

\subsection{Method}

The grinding experiments were performed by a Union Process STD-01 batch-type laboratory scale pin-type vertical stirred mill with a $750 \mathrm{cc}$ ceramic $\left(\mathrm{Al}_{2} \mathrm{O}_{3}\right)$ tank (see Figure 2$)$. The stirrer axis was fitted with a shaft and four arms. The shaft length was $26.6 \mathrm{~cm}$, the length of each mixing arm was $5.7 \mathrm{~cm}$ and the distance of the shaft from the bottom of the tank was $0.635 \mathrm{~cm}$. The grinding tank also had a water jacket to ensure cooling, and the temperature was set at $18{ }^{\circ} \mathrm{C}$ using a PolyScience PP07R-20 (PolyScience, Illinois, USA) water circulator. 
Table 1. The chemical composition and basic physical characteristics of the calcite specimen.

\begin{tabular}{cc}
\hline Constituent & Content (\%) \\
\hline Chemical composition & \\
\hline $\mathrm{CaCO}_{3}$ & 99.5 \\
$\mathrm{MgCO}_{3}$ & 0.2 \\
$\mathrm{Fe}_{2} \mathrm{O}_{3}$ & 0.01 \\
$\mathrm{SiO}_{2}$ & 0.01 \\
$\mathrm{Al}_{2} \mathrm{O}_{3}$ & 0.02 \\
$\mathrm{LOI}^{*}$ & 0.26 \\
\hline Physical properties \\
Average particle size, $\mathrm{d} 50(\mu \mathrm{m})$ & 11 \\
Specific gravity $\left(\mathrm{kg} / \mathrm{m}^{3}\right)$ & 2700 \\
\hline
\end{tabular}

LOI *loss on ignition.

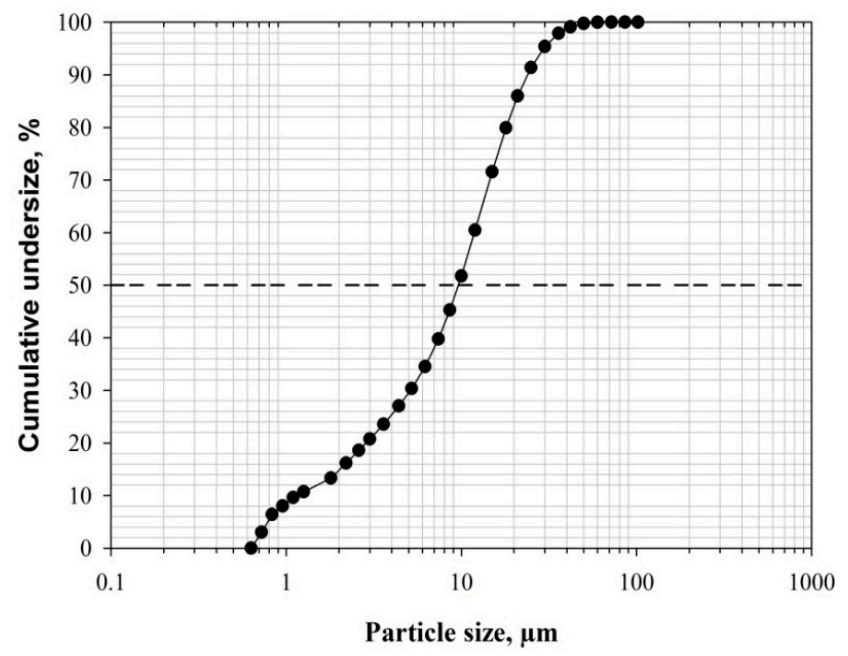

Figure 1. The particle size distribution of the feed material for grinding.

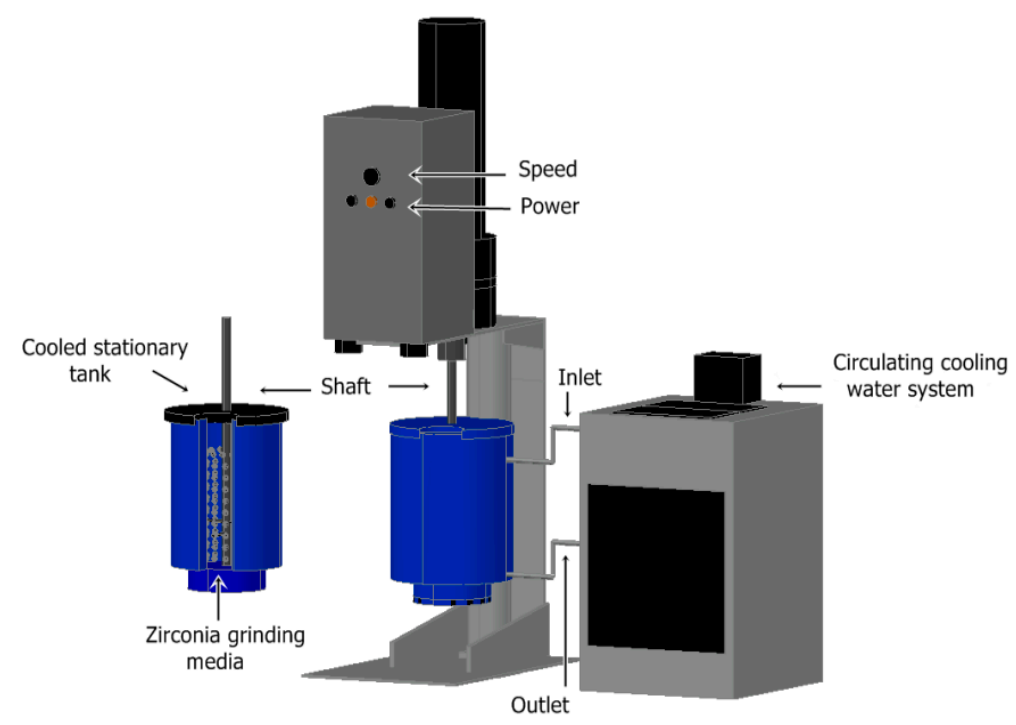

Figure 2. Schematic diagram of the experimental setup used for grinding.

The grinding experiments were realized as a batch process with calcite specimens received from the grinding tank in a detected grinding-time interval. All of the media and calcite specimens were 
detracted from the stirred media mill after each experiment, and the grinding media were separated from the calcite specimens as a result of dry sieving. A Wet Laser Diffraction Particle Sizer Malvern 2000 Ver. 2.00 with Hydro 2000 G attachment (Malvern Co., Ltd., Malvern, UK) was utilized to analyze the feed and ground products. Each test was performed in triplicate, and the reported values represented a mean average. In this study, the main aim was to detect the best design of variables that might be utilized in grinding to produce the minimum product particle size $\left(\mathrm{d}_{50}\right)$. X-ray diffraction (XRD) patterns were recovered by utilizing PANalytical Empyrean for the analysis of crystal structures of the calcite specimens. The $\mathrm{CuK} \alpha(\lambda=0.15418 \mathrm{~nm})$ radiation filtered by Ni was utilized for the purpose of recording patterns in the diffraction angle of $2 \theta$ ranging from $5^{\circ}$ to $70^{\circ}$ with a measuring time of $8 \mathrm{~s}$ at every angle.

\subsection{Experiment Design}

To elucidate the effect of a number of operating parameters using a stirred media mill on the dry grinding of calcite, a four-factor three-level Box-Behnken response surface design was employed using statistical software (Design Expert 7.0.0). One of the advantages of the Box-Behnken design for 3-10 factors is that it is a global design and has only three levels of data, with low $(-1)$, center $(0)$ and high $(+)$ as coded levels. The Box-Behnken design is capable of significantly decreasing the number of experiments without reducing the optimization accuracy, in comparison with conventional factorial design methods. An experiment number in accordance with Equation (1) is required by the Box-Behnken design:

$$
\mathrm{N}=\mathrm{K}^{2}+\mathrm{k}+\mathrm{c}_{\mathrm{p}}
$$

where $(k)$ denotes the number of factors, and $\left(c_{p}\right)$ denotes the replicate number of the central point [31-33].

The examined factors chosen as independent variables were the stirrer speed, $\mathrm{SS}\left(X_{1}, \mathrm{rpm}\right)$; grinding time, GT $\left(X_{2}, \mathrm{~min}\right)$; the media filling ratio, $\operatorname{MFR}\left(X_{3}, \%\right)$; and the solid mass fraction, $\mathrm{SMF}$ $\left(X_{4}, \%\right)$. The obtained experimental results were assessed by statistical analysis utilizing the same software package. The factors and coded levels in the current research are presented in Table 2.

Table 2. Experimental factors and their corresponding levels.

\begin{tabular}{ccccc}
\hline \multirow{2}{*}{ Factors } & \multirow{2}{*}{ Factor Code } & \multicolumn{3}{c}{ Coded Levels } \\
\cline { 3 - 5 } & & Low (-) & Center (0) & High (+) \\
\hline Stirrer speed, SS (rpm) & $X_{1}$ & 300 & 450 & 600 \\
Grinding time, GT (min.) & $X_{2}$ & 5 & 10 & 15 \\
Media filling ratio, MFR (\%) & $X_{3}$ & 50 & 60 & 70 \\
Solid mass fraction, SMF (\%) & $X_{4}$ & 10 & 12 & 14 \\
\hline
\end{tabular}

\section{Results and Discussion}

For RSM including the Box-Behnken experimental design, a total of 27 tests with the appropriate combinations of SS $\left(X_{1}, \mathrm{rpm}\right), \mathrm{GT}\left(X_{2}, \mathrm{~min}\right), \operatorname{MFR}\left(X_{3}, \%\right)$, and SMF $\left(X_{4}, \%\right)$ were conducted for each of the four factors at the three levels.

Each experiment was repeated twice, and the reported $d_{50}$ values are the mean average. Table 3 presents a summary of the experimental series, their factor combinations, and the levels of the experimental units utilized in the research, in addition to the mean particle size acquired for every combination of factors. 
Table 3. Box-Behnken design and actual results.

\begin{tabular}{|c|c|c|c|c|c|c|c|c|c|}
\hline \multirow{2}{*}{$\begin{array}{l}\text { Run } \\
\text { No. }\end{array}$} & \multicolumn{4}{|c|}{ Coded Levels of Factors } & \multicolumn{4}{|c|}{ Real Factors } & \multirow[t]{2}{*}{ Actual Result } \\
\hline & $X_{1}$ & $X_{2}$ & $X_{3}$ & $X_{4}$ & SS & GT & MFR & SMF & \\
\hline & & & & & rpm & $\min$ & $\%$ & $\%$ & $\mu \mathrm{m}$ \\
\hline 1 & 1 & 0 & -1 & 0 & 600 & 10 & 50 & 12 & 4.49 \\
\hline 2 & 0 & 0 & 1 & -1 & 450 & 10 & 70 & 10 & 4.7 \\
\hline 3 & 1 & 0 & 0 & 1 & 600 & 10 & 60 & 14 & 4.62 \\
\hline 4 & 0 & 1 & 1 & 0 & 450 & 15 & 70 & 12 & 4.18 \\
\hline 5 & 0 & 0 & -1 & 1 & 450 & 10 & 50 & 14 & 5.68 \\
\hline 6 & -1 & 1 & 0 & 0 & 300 & 15 & 60 & 12 & 5.35 \\
\hline 7 & 0 & -1 & 0 & -1 & 450 & 5 & 60 & 10 & 5.8 \\
\hline 8 & 0 & 0 & -1 & -1 & 450 & 10 & 50 & 10 & 5.44 \\
\hline 9 & 0 & 0 & 0 & 0 & 450 & 10 & 60 & 12 & 4.12 \\
\hline 10 & 1 & 0 & 1 & 0 & 600 & 10 & 70 & 12 & 4.2 \\
\hline 11 & 0 & 1 & 0 & 1 & 450 & 15 & 60 & 14 & 5.02 \\
\hline 12 & -1 & 0 & 0 & 1 & 300 & 10 & 60 & 14 & 6.2 \\
\hline 13 & 1 & 0 & 0 & -1 & 600 & 10 & 60 & 10 & 4.5 \\
\hline 14 & -1 & 0 & 0 & -1 & 300 & 10 & 60 & 10 & 5.4 \\
\hline 15 & -1 & 0 & -1 & 0 & 300 & 10 & 50 & 12 & 6.5 \\
\hline 16 & -1 & -1 & 0 & 0 & 300 & 5 & 60 & 12 & 7.01 \\
\hline 17 & 0 & 1 & -1 & 0 & 450 & 15 & 50 & 12 & 5.04 \\
\hline 18 & -1 & 0 & 1 & 0 & 300 & 10 & 70 & 12 & 5.35 \\
\hline 19 & 0 & 1 & 0 & -1 & 450 & 15 & 60 & 10 & 4.68 \\
\hline 20 & 1 & 1 & 0 & 0 & 600 & 15 & 60 & 12 & 3.96 \\
\hline 21 & 0 & 0 & 0 & 0 & 450 & 10 & 60 & 12 & 4.26 \\
\hline 22 & 1 & -1 & 0 & 0 & 600 & 5 & 60 & 12 & 4.28 \\
\hline 23 & 0 & 0 & 0 & 0 & 450 & 10 & 60 & 12 & 4.24 \\
\hline 24 & 0 & -1 & 0 & 1 & 450 & 5 & 60 & 14 & 6.4 \\
\hline 25 & 0 & -1 & 1 & 0 & 450 & 5 & 70 & 12 & 5.03 \\
\hline 26 & 0 & 0 & 1 & 1 & 450 & 10 & 70 & 14 & 4.78 \\
\hline 27 & 0 & -1 & -1 & 0 & 450 & 5 & 50 & 12 & 6.54 \\
\hline
\end{tabular}

\subsection{Models and ANOVA Analysis}

The outcomes of the experiments given in Table 3 were compiled with a full quadratic model by performing multiple regression analysis for $\mathrm{d}_{50}$. The final quadratic models of the response equation with regard to coded factors are given in Equation (2):

$$
\begin{gathered}
Y=54.35958-0.0282 X_{1}-0.90417 X_{2}-0.62692 X_{3}-2.97917 X_{4}+0.000443 X_{1} X_{2}+ \\
0.000143 X_{1} X_{3}-0.00056667 X_{1} X_{4}+0.00325 X 2 X_{3}-0.0065 X_{2} X_{4}-0.002 X_{3} X_{4}+ \\
0.0000183889 X_{1}^{2}+0.023700 X_{2}^{2}+0.0042375 X_{3}^{2}+0.14625 X_{4}^{2}
\end{gathered}
$$

In the equation, $Y$ represents the response $\left(\mathrm{d}_{50}\right) ; X_{1}, X_{2}, X_{3}$ and $X_{4}$ represent $\mathrm{SS}, \mathrm{GT}, \mathrm{MFR}$, and SMF, respectively.

The significance of the fitted quadratic models for $\mathrm{d}_{50}$ is evaluated by analysis of variance (ANOVA) and the F-test, as demonstrated in Table 4 . As the $F$-value increases, the $p$-value decreases [34]. The $p$-value for the term of models below 0.001 demonstrates the statistical significance of the models [32]. 
Table 4. Analysis of variance (ANOVA) for the fitted models.

\begin{tabular}{cccccc}
\hline Source & Sum of Squares & df & Mean Square & $\boldsymbol{F}$-Value & $p$-Value \\
\hline Model & 18.48 & 14 & 1.32 & 23.60 & $<0.0001$ \\
Residual & 0.67 & 12 & 0.056 & & \\
Total & 19.15 & 26 & & \\
\hline \multicolumn{2}{c}{ Model Summary } & & & \\
R-sq. & R-sq. (adj) & & & \\
0.965 & 0.9241 & & & \\
\hline
\end{tabular}

R-sq.: (R-Squared); adj.: Adjusted.

Furthermore, the determination coefficient $R^{2}$ is described as the ratio of the defined variation to the total variation, and it represents a measure of the degree of fit. With the approaching of $R^{2}$ to unity, there is a better fit of the response models to the actual data. The determination coefficient $R^{2}$ values for $d_{50}$ are 0.965 (see Figure 3). Accordingly, it is suggested that the $d_{50}$ models have a high goodness of fit and are capable of providing a satisfying prediction of the results of experiments.

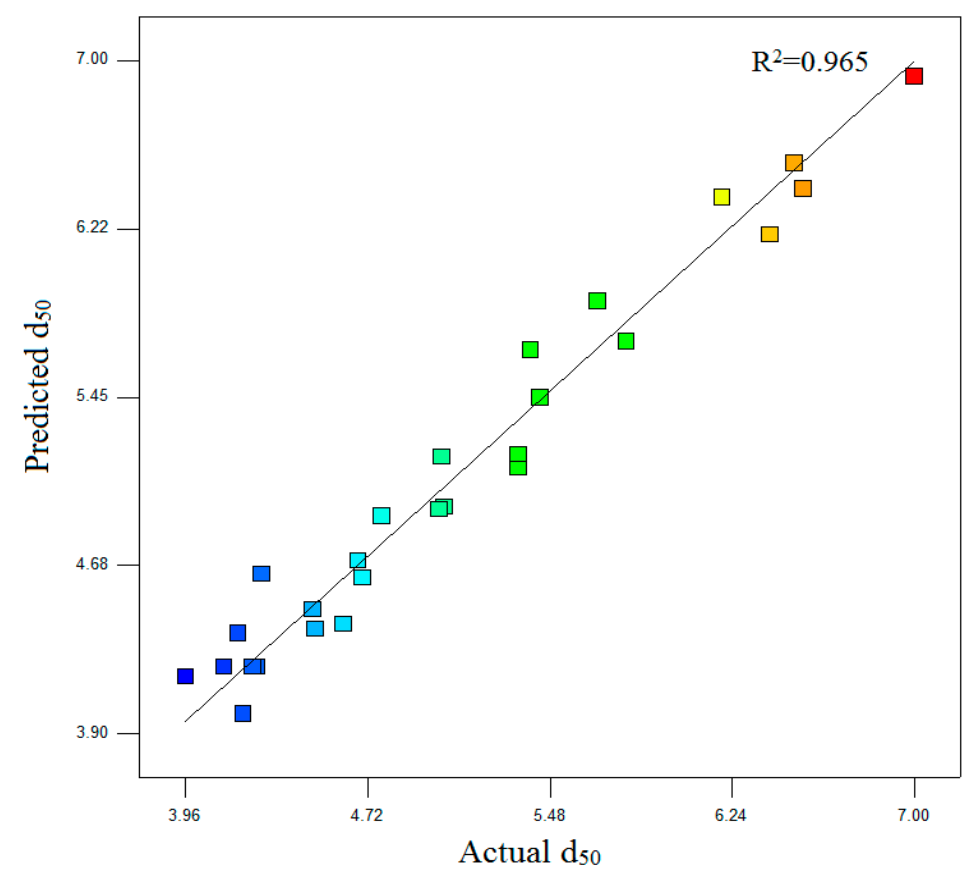

Figure 3. Relationship between actual and predicted $\mathrm{d}_{50}$ values.

\subsection{Three-Dimensional (3D) Response Surface Plots of the Factors}

The 3D response surface plots showing the mutual effects of factors on $d_{50}$ are presented in Figure $4 \mathrm{a}-\mathrm{f}$.

SS is one of the most important factors in stirred media mills. The particle size change graphs according to GT and SS are given in Figure 4a. In the experiments at 5 min GT, with an increase in SS from $300 \mathrm{rpm}$ to $600 \mathrm{rpm}$, a decrease in the $\mathrm{d}_{50}$ size from $7 \mu \mathrm{m}$ to $4.28 \mu \mathrm{m}$ occurred. As the graph indicates, interactions between GT and SS clearly affected the reduced particle size in a positive way, and the $d_{50}$ size could be reduced to $3.96 \mu \mathrm{m}$.

As is seen in Figure 4b, with an increase in MFR from 50\% to $70 \%$ and an increase in SS from $300 \mathrm{rpm}$ to $600 \mathrm{rpm}$, a decrease in the $\mathrm{d}_{50}$ size from $6.5 \mu \mathrm{m}$ to $4.2 \mu \mathrm{m}$ occurred. This clearly shows that the increase in MFR did not affect the $d_{50}$ size significantly. However, it increased the mill's power draw $[35,36]$. 


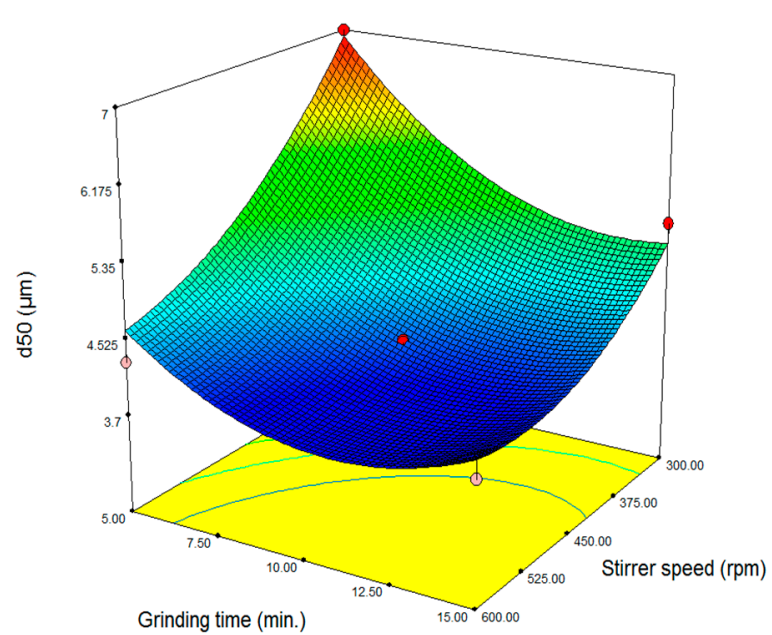

(a)

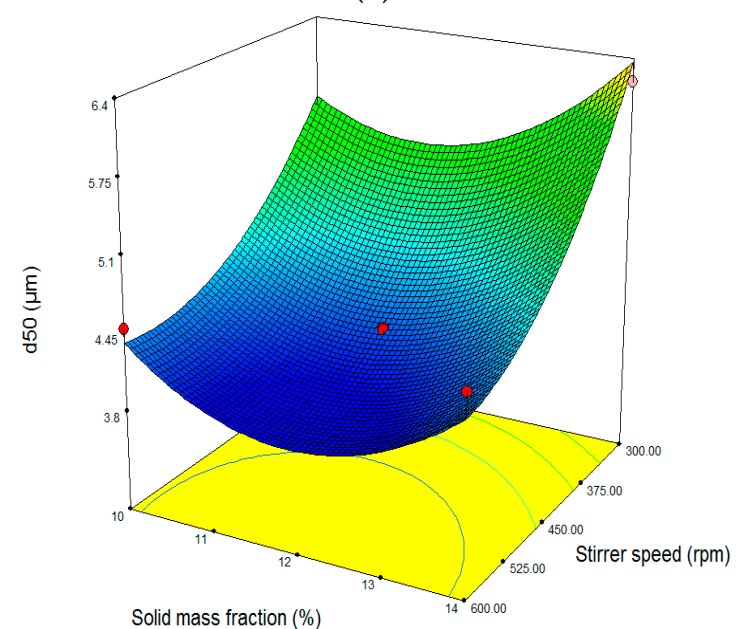

(c)

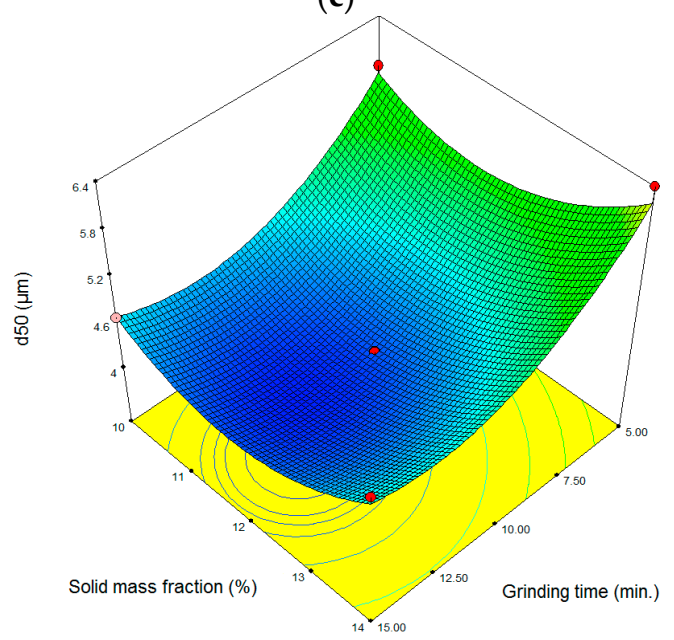

(e)

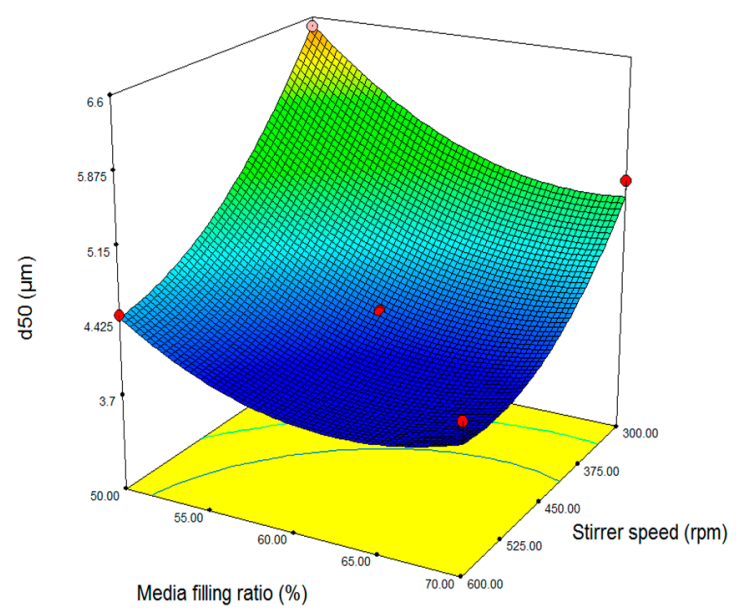

(b)

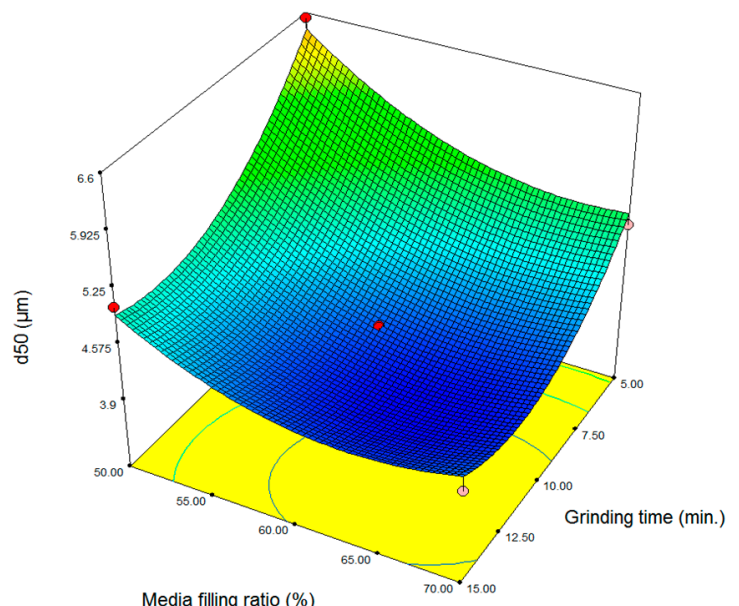

(d)

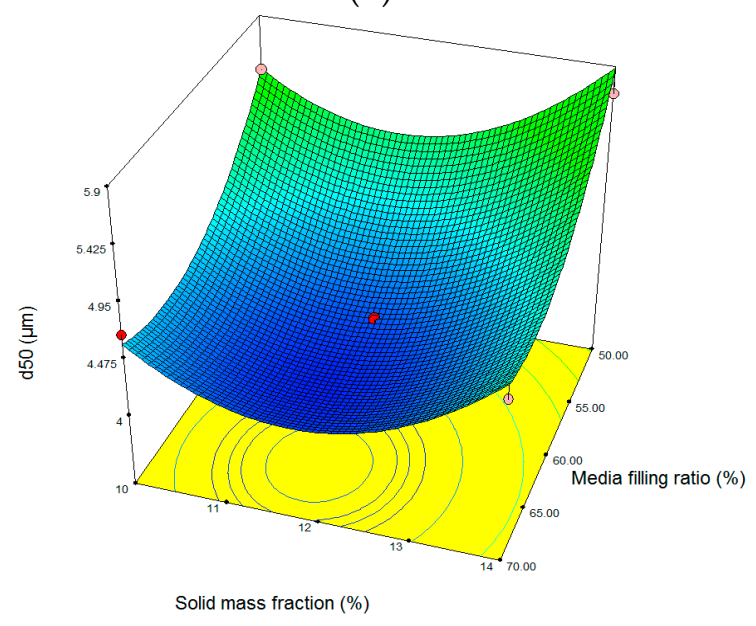

(f)

Figure 4. Response surface plots of $d_{50}(\mu \mathrm{m})$ as a function of: (a) grinding time ( $\mathrm{min}$ ) and stirrer speed (rpm); (b) media filling ratio (\%) and stirrer speed (rpm); (c) solid mass fraction (\%) and stirrer speed $(\mathrm{rpm}) ;(\mathbf{d})$ media filling ratio (\%) and grinding time ( $\mathrm{min}) ;(\mathbf{e})$ solid mass fraction (\%) and grinding time (min); (f) solid mass fraction (\%) and media filling ratio (\%). 
Figure $4 \mathrm{c}$ indicates that SMF did not significantly affect the $d_{50}$ size. Nevertheless, SS clearly affected the particle size, and the minimum $\mathrm{d}_{50}$ size was obtained at the maximum level of SS (600 rpm) and the midpoint of SMF (12\%).

It is observed from Figure $4 \mathrm{~d}$ that, as the values of MFR and GT increase, the $d_{50}$ size becomes minimized and reaches $4.18 \mu \mathrm{m}$. In other words, the minimum $\mathrm{d}_{50}$ size was obtained nearly at the maximum points of both factors MFR and GT.

According to Figure 4e, when GT decreased and SMF increased, the $d_{50}$ size was maximized and reached $6.4 \mu \mathrm{m}$. The desirable point of $\mathrm{d}_{50}$ was obtained at the midpoint of SMF and nearly at the maximum level of GT. A high solid mass fraction induces a short mean inter-particle distance, and the particle-particle interactions become more widespread. Therefore, the free motion of particles is disturbed [37].

Figure $4 \mathrm{f}$ indicates that the increase in SMF did not greatly affect the reduction of particle size. Furthermore, the minimum particle size of $d_{50}$ was obtained at the midpoint of SMF and MFR. By increasing the media filling ratio, the particles move strongly and are located along outer wall of grinding vessel. They then show a regular speed profile. Furthermore, the impact energy increases to a certain level of the media filling ratio and the size of the particles decreases. While the collision frequency between particles increases, collision energy decreases. Re-agglomeration may occur between fine particles at a higher media filling ratio. As the media filling ratio is further increased, the possible result is an increase in particle size [10].

\subsection{Optimization and Verification Tests}

Using Design-Expert software, the optimization function was utilized for the purpose of acquiring the optimal conditions for the $\mathrm{d}_{50}$ size. According to the software solutions, the optimum conditions for minimizing the $d_{50}$ size were found to be $573 \mathrm{rpm} \mathrm{SS}, 11.18 \mathrm{~min}$ GT, 63\% MFR, and $11.52 \% \mathrm{SMF}$, with $3.78 \mu \mathrm{m}$ for the $d_{50}$ size. To verify the improvement in grinding, verification tests were performed in triplicate using the above-mentioned optimum conditions. Subsequently, each test was performed three times in the Malvern Mastersizer, and the reported values represent a mean average. Figure 5 shows the statistical evaluation of the measurement values of the $d_{50}$ size.

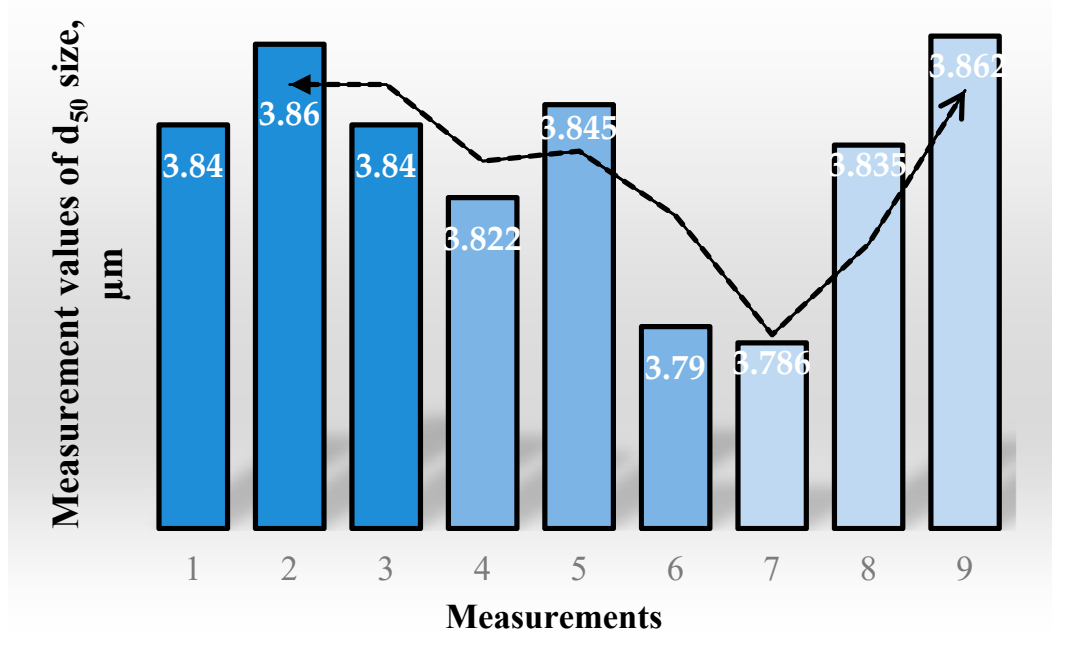

Figure 5. Statistical evaluation of measurement values of the $\mathrm{d}_{50}$ size.

According to the measurement results, the mean average and standard deviation of the $d_{50}$ size were found to be $3.83 \mu \mathrm{m}$ and 0.025 , respectively. This average $d_{50}$ value obtained was smaller than those obtained in the 27 tests. Furthermore, when the optimum result obtained from the experiments (Run: 20) was compared with the result obtained using the software, a $22 \%$ energy saving was achieved 
(Table 5) [36]. The optimization of energy consumption as a result of detecting operational parameters for the stirred media mill is crucial.

Table 5. Comparing the optimum actual and predicted result.

\begin{tabular}{ccc}
\hline & Optimum Actual Result & Optimum Predicted Result \\
\hline $\mathrm{d}_{50}(\mu \mathrm{m})$ & 3.96 & 3.83 \\
Energy consumption $(\mathrm{kWh} / \mathrm{ton})$ & 34.5 & 26.9 \\
\hline
\end{tabular}

\subsection{XRD Analysis}

The impacts of grinding on the structural characteristics of calcite were examined by X-ray diffraction analysis (Figure 6). No change was observed in the peak areas of the ground calcite specimens, compared to the untreated calcite specimen. However, the peak intensities of the optimum predicted result and optimum actual result decreased after milling as a consequence of the reduction in crystal size of a mineral [38]. Further, the lowest peak intensity was obtained in the optimum predicted result.

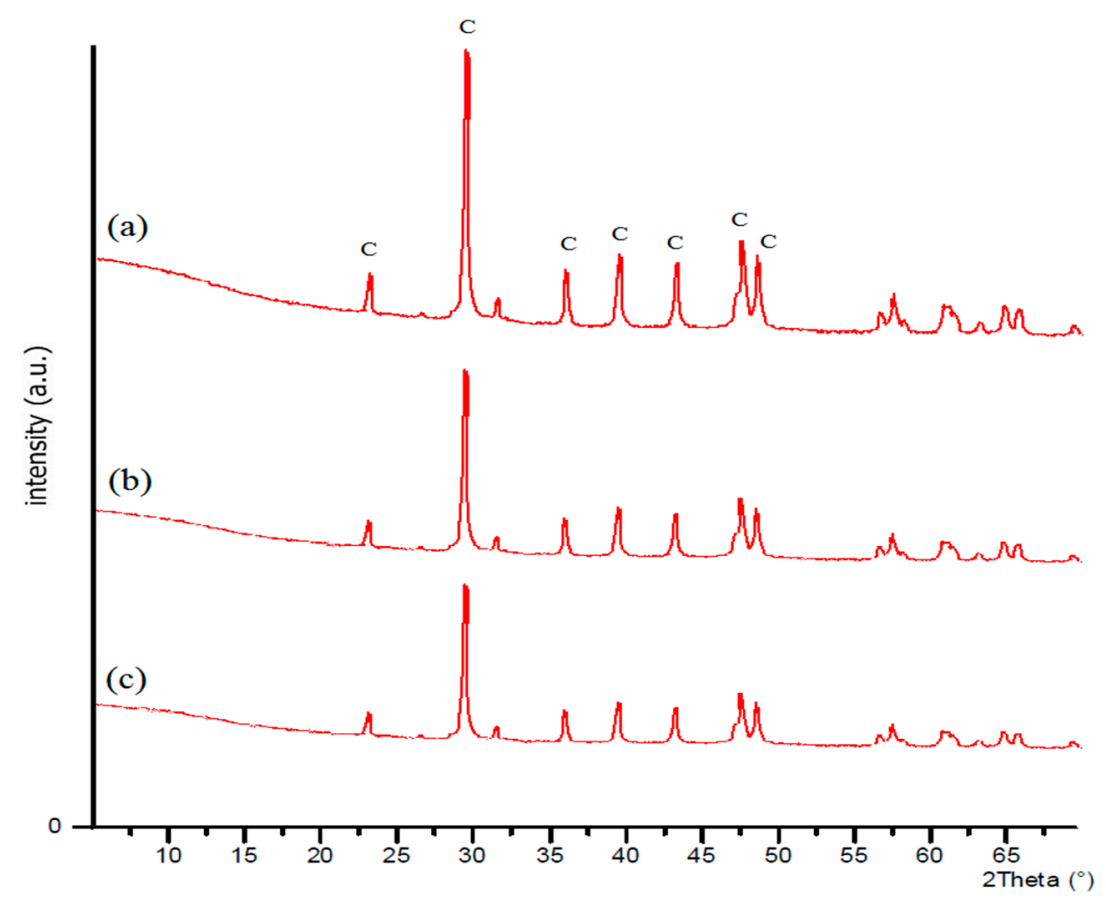

Figure 6. X-ray diffraction analysis of calcite: (a) feed; (b) optimum actual result; (c) optimum predicted result. C: Calcite.

\section{Conclusions}

The fundamental goal of this study was the optimization of a number of operating parameters of a stirred media mill on the dry grinding of calcite. A three-level Box-Behnken design was used for the purpose of examining the impact of four independent factors - the stirrer speed, grinding time, media filling ratio, and solid mass fraction - on the product particle size $\left(\mathrm{d}_{50}\right)$. The final quadratic models of the response equation with regard to coded factors were derived for $d_{50}$ sizes. Variance analysis showed quite a good value for $d_{50}\left(R^{2}=0.965\right)$. According to the software solutions, the optimum conditions for minimizing the $\mathrm{d}_{50}$ size were found to be $573 \mathrm{rpm} \mathrm{SS}, 11.18 \mathrm{~min}$ GT, 63\% MFR, and $11.52 \% \mathrm{SMF}$, with $3.78 \mu \mathrm{m}$ for the $d_{50}$ size. In the verification test, the $d_{50}$ size was obtained to be $3.83 \mu \mathrm{m}$ under the optimum predicted conditions in accordance with the optimum actual result. Furthermore, when the optimum result obtained from the experiments (Run: 20) was compared with the result obtained 
using the software, a $22 \%$ energy saving was achieved. The impacts of grinding on the structural characteristics of calcite particles were characterized by XRD analysis. XRD measurements indicated that no change was observed in the peak areas of ground calcite specimens compared to the untreated calcite specimen. The lowest peak intensity was obtained in the optimum predicted result.

This study has shown that it is possible to achieve energy saving as a result of the optimization of the mill's parameters. Thus, it is possible to successfully utilize RSM to optimize operating parameters of a stirred media mill. Moreover, this study is important in terms of the efficient and effective use of material and time, the support for environmental protection, and the determination of operating parameters faced in previous studies.

Funding: This research received no external funding.

Acknowledgments: The author would like to thank Mertas Company (Nigde, Turkey) for providing the sample for the present study.

Conflicts of Interest: The author declares no conflict of interest.

\section{References}

1. Rungruang, P.; Grady, B.P.; Supaphol, P. Surface-modified calcium carbonate particles by admicellar polymerization to be used as filler for isotactic polypropylene. Colloids Surf. A Physicochem. Eng. Asp. 2006, 275, 114-125. [CrossRef]

2. Sheng, Y.; Zhou, B.; Zhao, J.; Tao, N.; Yu, K.; Tian, Y.; Wang, Z. Influence of octadecyl dihydrogen phosphate on the formation of active super-fine calcium carbonate. J. Colloid Interface Sci. 2004, 272, 326-329. [CrossRef] [PubMed]

3. Yang, Y.C.; Jeong, S.B.; Yang, S.Y.; Chae, Y.B.; Kim, H.S. The changes in surface properties of the calcite powder with stearic acid treatment. Mater. Trans. 2009, 50, 695-701. [CrossRef]

4. Deodhar, S.; Shanmuganathan, K.; Patra, P.; Fan, Q.; Calvert, P.; Warner, S. Technical Papers in Composites, Convention and Trade Show. In Polypropylene Based Novel Flame Retardant Nanocomposite Composition; American Composite Manufacturers Association: St Louis, MO, USA, 2006; pp. 1-16.

5. Xu, X.; Tao, X.; Gao, C.; Zheng, Q. Studies on the steady and dynamic rheological properties of poly(Dimethyl-Siloxane) filled with calcium carbonate based on superposition of its relative functions. J. Appl. Polym. Sci. 2008, 107, 1590-1597. [CrossRef]

6. Pilevneli, C.C.; Kızgut, S.; Toroğlu, I.; Çuhadaroğlu, D.; Yiğit, E. Open and closed circuit dry grinding of cement mill rejects in a pilot scale vertical stirred mill. Powder Technol. 2004, 139, 165-174. [CrossRef]

7. Toraman, O.Y. Dry fine grinding of calcite powder by stirred mill. Part. Sci. Technol. 2013, 31, $205-209$. [CrossRef]

8. Prziwara, P.; Hamilton, L.D.; Breitung-Faes, S.; Kwade, A. Impact of grinding aids and process parameters on dry stirred media milling. Powder Technol. 2018, 335, 114-123. [CrossRef]

9. Altun, O.; Benzer, H.; Enderle, U. Effects of operating parameters on the efficiency of dry stirred milling. Miner. Eng. 2013, 43, 58-66. [CrossRef]

10. Mucsi, G.; Rácz, Á.; Mádai, V. Mechanical activation of cement in stirred media mill. Powder Technol. 2013, 235, 163-172. [CrossRef]

11. Rácz, Á.; Csőke, B. Application of the product related stress model for product dispersity control in dry stirred media milling. Int. J. Miner. Process. 2016, 157, 28-35. [CrossRef]

12. Prziwara, P.; Breitung-Faes, S.; Kwade, A. Impact of powder flow behavior on continuous fine grinding in dry operated stirred media mills. Miner. Eng. 2018, 128, 215-223. [CrossRef]

13. Orumwense, O.A. The Effect of Media Type on Regrinding with Stirred Mills; SME Annual Meeting: Salt Lake City, UT, USA, 2005.

14. Celep, O.; Yazıcı, E.Y. Ultra fine grinding of silver plant tailings of refractory ore using vertical stirred media mill. Trans. Nonferrous Met. Soc. China 2013, 23, 3412-3420. [CrossRef]

15. Ouattara, S.; Frances, C. Grinding of calcite suspensions in a stirred media mill: Effect of operational parameters on the product quality and the specific energy. Powder Technol. 2014, 255, 89-97. [CrossRef]

16. Jankovic, A. Variables affecting the fine grinding of minerals using stirred mills. Miner. Eng. 2003, 16, 337-345. [CrossRef] 
17. Wang, Y.; Forssberg, E.; Sachweh, J. Dry fine comminution in a stirred media mill- MaxxMill ${ }^{\circledR}$. Int. J. Miner. Process. 2004, 74, 65-74. [CrossRef]

18. Jayasundara, C.T.; Yang, R.Y.; Yu, A.B.; Rubenstein, J. Effects of disc rotation speed and media loading on particle flow and grinding performance in a horizontal stirred mill. Int. J. Miner. Process. 2010, 96, 27-35. [CrossRef]

19. Hamey, R.G. Production of Organic Pigment Nanoparticles by Stirred Media Milling. Ph.D. Thesis, The University of Florida, Gainesville, FL, USA, 2005.

20. Gao, M.; Holmes, R.; Pease, J. The Latest Developments in Fine and Ultrafine Grinding Technologies, XXIII; International Mineral Processing Congress: Istanbul, Turkey, 2006; pp. 30-37.

21. Lichter, J.K.H.; Davey, G. Advances in Comminution. In Selection and Size of Ultrafine and Stirred Grinding Mills; Komar Kawatra, S., Ed.; Society for Mining Metallurgy and Exploration Inc.: Denver, CO, USA, 2006; pp. 69-86.

22. Celep, O.; Aslan, N.; Alp, I.; Tasdemir, G. Optimization of some parameters of stirred mill for ultra fine grinding of refractory Au/Ag ores. PowderTechnol. 2011, 208, 121-127. [CrossRef]

23. Anderson-Cook, C.M.; Borror, C.M.; Montgomery, D.C. Response surface design evaluation and comparison. J. Stat. Plan. Inference 2009, 139, 629-641. [CrossRef]

24. Hasan, M.; Palaniandy, S.; Hilden, M.; Powell, M. Calculating breakage parameters of a batch vertical stirred mill. Miner. Eng. 2017, 111, 229-237. [CrossRef]

25. Gibson, C.E.; Hansuld, R.; Kelebek, S.; Aghamirian, M. Behaviour of ilmenite as a gangue mineral in the benzohydroxamic flotation of a complex pyrochlore-bearing ore. Miner. Eng. 2017, 109, 98-108. [CrossRef]

26. Kirboga, S.; Öner, M. Investigating the effect of ultrasonic irradiation on synthesis of calcium carbonate using Box-Behnken experimental design. Powder Technol. 2017, 308, 442-450. [CrossRef]

27. Celep, O.; Altinkaya, P.; Yazici, E.Y.; Deveci, H. Thiosulphate leaching of silver from an arsenical refractory ore. Miner. Eng. 2018, 122, 285-295. [CrossRef]

28. Shukla, D.; Venugopal, R. Optimization of the process parameters for fine coal-oil agglomeration process using waste mustard oil. Powder Technol. 2019, 346, 316-325. [CrossRef]

29. Pariyan, K.; Hosseini, M.R.; Ahmadi, A.; Zahiri, A. Optimization and kinetics of oxalic acid treatment of feldspar for removing the iron oxide impurities. Sep. Sci. Technol. 2019, in press. [CrossRef]

30. Rahmati, S.; Ahmadi, A.; Hosseini, M.R.; Nasab, M.M. Optimization of continuous air-assisted solvent extraction for treating dilute $\mathrm{Cu}$ leach solutions using response surface methodology. Miner. Eng. 2019, 13, 154-163. [CrossRef]

31. Ferreira, S.L.; Bruns, R.E.; Ferreira, H.S.; Matos, G.D.; David, J.M.; Brandão, G.C.; da Silva, E.G.; Portugal, L.A.; dos Reis, P.S.; Souza, A.S.; et al. Box-Behnken design: An alternative for the optimization of analytical methods. Anal. Chim. Acta 2007, 597, 179-186. [CrossRef] [PubMed]

32. Montgomery, D.C. Design and Analysis of Experiments; John Wiley and Sons: Hoboken, NY, USA, 2001.

33. Myers, R.H.; Montgomery, D.C. Response Surface Methodology: Process and Product Optimization Using Designed Experiments; John Wiley and Sons: Hoboken, NY, USA, 2002.

34. Atkinson, A.C.; Donev, A.N. Optimum Experimental Designs; University of Oxford: Oxford, UK, 1992.

35. Jankovic, A. Media stress intensity analysis for vertical stirred mills. Miner. Eng. 2001, 14, 1177-1186. [CrossRef]

36. Katircioglu-Bayel, D.; Ozkan, S.G.; Toraman, O.Y. Effect of operating parameters on the breakage process of calcite in a stirred media mill. Min. Metall. Explor. 2019, 36, 399-408. [CrossRef]

37. He, M.; Wang, Y.; Forssberg, E. Parameter effects on wet ultrafine grinding of limestone through slurry rheology in stirred media mill. Powder Technol. 2006, 161, 10-21. [CrossRef]

38. Mochalin, V.N.; Sagar, A.; Gour, S.; Gogotsi, Y. Manufacturing nanosized fenofibrate by salt assisted milling. Pharm. Res. 2009, 26, 1365-1370. [CrossRef]

(C) 2020 by the author. Licensee MDPI, Basel, Switzerland. This article is an open access article distributed under the terms and conditions of the Creative Commons Attribution (CC BY) license (http://creativecommons.org/licenses/by/4.0/). 